\title{
An Analytical Strategy for Quaternary Ammonium Neuromuscular Blocking Agents in a Forensic Setting Using LC-MS/MS on a Tandem Quadrupole/ Time-of-Flight Instrument
}

\author{
Kevin D. Ballard, William E. Vickery, Loan T. Nguyen, \\ and Francis X. Diamond \\ NMS Labs, Willow Grove, Pennsylvania, USA
}

\author{
Fredric Rieders \\ The Fredric Rieders Family Renaissance Foundation, Willow Grove, Pennsylvania, USA
}

\begin{abstract}
An analytical strategy is described for analyzing quaternary ammonium neuromuscular blocking agents in a wide variety of biological specimens in a forensic setting. Neuromuscular blocking agents such as succinylcholine, pancuronium, and tubocurarine, often used as paralytic agents during surgery, are occasionally suspected as paralytic poisoning agents involved in suspected homicide and suicide cases. Because suspicion in such cases can develop slowly, the age, nature, and quality of available specimens varies greatly. The compounds are challenging analytically because of their simultaneous precharged yet lipophilic character. An analytical strategy has been devised for extracting these compounds from complex matrices using a combination of a modified Bligh and Dyer liquid-liquid extraction (used in reverse) followed by reverse-phase ion pairing solid-phase extraction using heptafluorobutyric acid as an ion pairing reagent. Final analysis is by LC-MS/MS using a tandem quadrupole orthogonal acceleration time of flight instrument (Q-TOF) with repetitive product ion scanning at high resolution. Native and spiked specimens are compared for both quantitative and especially qualitative purposes. The method has been applied to a wide variety of fluid and tissue specimen types, including numerous specimens from exhumation autopsies. For most specimens, detection limits are in the 2 to $10 \mathrm{ng} / \mathrm{g}$ range. Succinylmonocholine has been demonstrated to be present at low levels in normal posthumous kidney and liver. The Q-TOF is an excellent platform for forensic analytical investigations. This analytical strategy should also be applicable to other problematic analytes and sample matrices. (J Am Soc Mass Spectrom 2006, 17, 1456-1468) (c) 2006 American Society for Mass Spectrometry
\end{abstract}

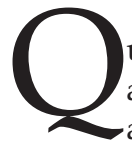

uaternary ammonium neuromuscular blocking agents are paralytic drugs used primarily by anesthesiologists to paralyze patients during surgical procedures. They are also used as paralytic agents in veterinary and laboratory animal medicine. Drugs in this category include well-known compounds such as succinylcholine, tubocurarine (curare), and pancuronium. Pharmacologically, these drugs block the effects of the neurotransmitter acetylcholine in skeletal muscle, resulting in the paralysis of all voluntary muscles and the diaphragm, the principal muscle of breathing. Thus, a patient exposed to a clinically effective dose

Published online August 2, 2006

Address reprint requests to Dr. K. D. Ballard, Research and Development, NMS Labs, 3701 Welsh Rd., Willow Grove, PA 19090, USA. E-mail: kevin.ballard@nmslab.com of one or more of these drugs cannot breathe on his own, and some form of artificial ventilation must be provided whenever these drugs are used, typically in the form of a mechanical respirator. The dose relationships and duration of action of these drugs are well known and generally quite predictable, and there is little clinical need to measure blood or urine levels of these drugs, except in possible accidental overdose situations or instances of unexpected, prolonged paralysis.

In terms of toxicity and forensics, a clinically effective dose of one of these drugs can also be a lethal dose if respiratory assistance is not provided. Thus, neuromuscular blocking agents are potential murder weapons. They may be particularly attractive to a potential poisoner because they are not routinely measured and, indeed, few forensic laboratories will even attempt to 
analyze these compounds. This is partially because there is little need to measure them clinically and, thus, no routine assays are available, and partially because they are analytically challenging compounds. Nevertheless, the potential for their use as murder weapons must be considered, particularly in cases involving sudden, unexpected, and unexplained death with a medical professional as a potential suspect, both within and outside of a hospital setting. Succinylcholine in particular has a long reputation as an undetectable, "perfect" poison.

The analysis of quaternary ammonium neuromuscular blocking agents in a forensic setting is challenging for two reasons. The first reason is that the chemical behavior of these compounds, involving both hydrophilic and lipophilic characteristics, makes them difficult to isolate from biological specimens. The second reason is the extraordinary variability of the types of specimens encountered; this variability is such that each specimen must be considered unique. This laboratory now has approximately six years of experience with these analyses, involving more than 450 tissue and fluid specimens, very few of which could be considered to be alike. Specimens have included some relatively fresh clinical liquid samples such as blood, plasma, and urine, but the vast majority of the specimens have been tissues. Some of these specimens were from autopsies conducted immediately after the death. Some of these had been refrigerated, some were frozen, some were formalin-fixed, and some were embedded in paraffin blocks. Some were from a decedent who had been embalmed before autopsy but not yet buried, with the specimens then frozen for several years. Some were from decedents who were embalmed, buried for one to ten years, then exhumed and autopsied. Some of the latter autopsy specimens were then stored frozen for several years before analysis. With this variability in the history and condition of the specimens, no two liver samples and no two kidney samples could be considered alike (even from the same decedent).

Because each of these specimens is unique and cannot legitimately be duplicated, it is not possible to "validate" the analytical methods for these samples in the usual sense of that term, which involves large numbers of identical known specimens and statistical analyses for precision and accuracy. The approach of this laboratory was to develop a method that was intended to be broadly applicable to a wide variety of specimens, to ensure that the method works very well for pristine samples such as spiked serum standards and spiked tissue homogenates, and then to apply the method to unique specimens in such a way that each specimen serves as its own control, both qualitatively and quantitatively, using the well-known method of standard additions [1, 2]. The analytical methods described here are currently being applied in this laboratory to the following neuromuscular blocking agents and/or their breakdown products: succinylcholine, succinylmonocholine, pancuronium, vecuronium, tubocu-
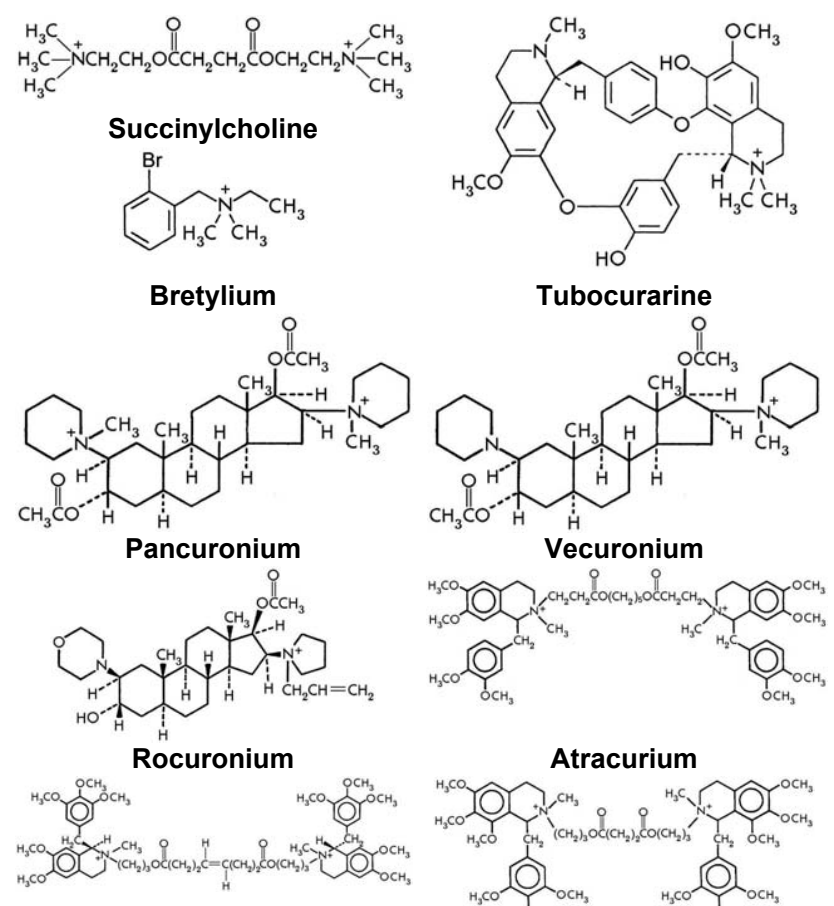

Mivacurium

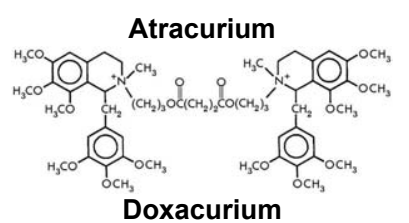

Table 1. Structures of the parent drugs

rarine, rocuronium, atracurium, mivacurium, and doxacurium. Since it is structurally similar and a potential poison, the quaternary cardiotonic drug bretylium is also included in this assay. Structures of the quaternary parent drugs involved in these studies are shown in Table 1, with additional structures of potentially significant breakdown products of some of the drugs shown in Table 2.

Initial studies indicated that several of these analytes, particularly the larger compounds such as pancuronium, bind extensively to the membranous components of tissues. Aqueous and standard liquid-liquid extraction approaches were inefficient for extracting these compounds. This observation was consistent with the simultaneous water-soluble yet highly lipophilic character of these compounds. An analytical strategy was devised to take advantage of the power of the Bligh and Dyer mixture for disrupting cell membranes [3]. The Bligh and Dyer mixture is a monophasic blend of water, methanol, and chloroform. The classic Bligh and Dyer procedure was originally intended for isolating lipids from plasma membranes in tissue specimens. Here, it is used in reverse (in slightly modified form), with the final aqueous component, rather than the organic component, taken as an initial extract. The second stage of extraction is a reverse phase ion pairing solid-phase extraction procedure using $\mathrm{C}_{18}$ extraction cartridges, with heptafluorobutyric acid used as an ion pairing reagent. This approach is derived from ion pairing principles originally intended for isolating peptides, but which are also applicable to quaternary ammonium compounds and to basic compounds in 


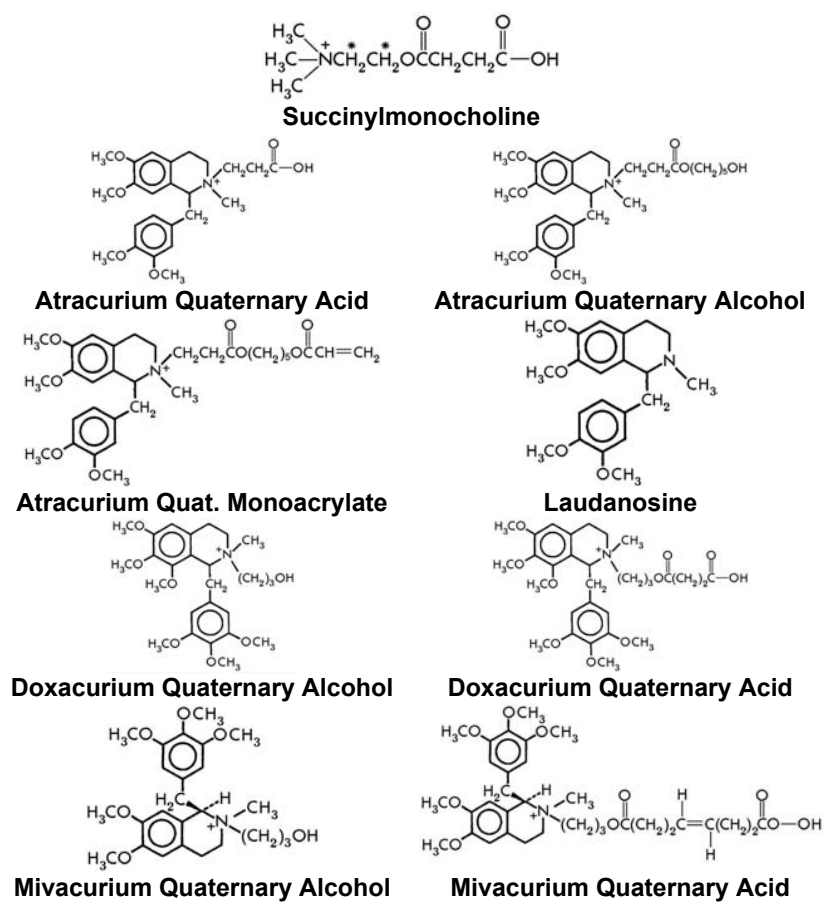

Table 2. Structures of potentially significant breakdown products derived from the parent drugs

general [4]. The analyses are internally standardized using $\left[{ }^{2} \mathrm{H}_{4}\right]$ succinylmonocholine as an internal standard. The overall method thus involves two stages of extraction based upon fundamentally different principles, with LC-MS/MS under ion pairing conditions as the analytical finish. This overall analytical strategy has proven to be very efficient for these challenging analytes in disparate sample types, and it may well be applicable to other challenging analytes with similar problematic characteristics, or for compounds that are highly compartmentalized in the intracellular space.

Since the most important question being addressed through these analyses usually concerns the qualitative presence or absence of these xenobiotics (with quantitative estimation usually of secondary importance), a major focus of this project was to incorporate into the analyses the qualitative power of the modern quadrupole/time-of-flight (Q-TOF) tandem mass spectrometer. Most liquid chromatography-tandem mass spectrometry (LC-MS/MS) analyses conducted in forensic laboratories involve monitoring only for two or three product ions characteristic of an analyte, using a tandem quadrupole instrument. The Q-TOF, however, which provides full scan product ion spectra at high resolution, has the potential to answer the qualitative question with a very high level of analytical confidence, and one of the goals of this project was to evaluate that potential in a forensic setting.

Several previous methods have been described for analyzing various neuromuscular blocking agents (and quaternary compounds in general) by mass spectrometric means [5-29]. In addition to incorporating the Q-
TOF, the analytical strategy described here is intended to provide high overall efficiency for numerous challenging analytes with a wide range of specimen types, particularly tissues in widely varying stages of preservation.

\section{Experimental}

\section{Materials}

Succinylcholine, succinylmonocholine, pancuronium, and tubocurarine were obtained from U.S. Pharmacopeia (Rockville, MD). Vecuronium and rocuronium were obtained as injectable solutions from Organon (West Orange, NJ). Atracurium, mivacurium, and doxacurium were obtained as injectable solutions from GlaxoWellcome (Research Triangle Park, NC). The solvents methanol, chloroform, and hexane were of Optima grade from Fisher (Pittsburg, PA). Heptafluorobutyric acid (HFBA) and choline chloride were from Sigma (St. Louis, MO). Solid-phase extraction columns were Varian (Harbor City, CA) Bond Elut- $\mathrm{C}_{18}$ columns with $500 \mathrm{mg}$ of bed material and a $3 \mathrm{ml}$ capacity. $\left[{ }^{2} \mathrm{H}_{9}\right]$ Choline chloride $\left(>99.5\right.$ atom $\left.\%{ }^{2} \mathrm{H}\right)$ was obtained from C/D/N Isotopes (Quebec, Canada). $\left[{ }^{2} \mathrm{H}_{8}\right]$ Succinylcholine $\left(98\right.$ atom $\left.\%{ }^{2} \mathrm{H}\right)$ was obtained as a custom synthesis from Medical Isotopes (Pelham, NH). $\left[{ }^{2} \mathrm{H}_{4}\right]$ Succinylmonocholine was generated in-house from the $\left[{ }^{2} \mathrm{H}_{8}\right]$ succinylcholine through hydrolysis at room temperature under mildly basic conditions (ammonium hydroxide, Fisher), with the hydrolysis stopped after full consumption of the starting material through acidification with formic acid (Fisher). Dilutions of the resulting solution were then compared by LC-MS/MS to unlabeled material to estimate the concentration of the $\left[{ }^{2} \mathrm{H}_{4}\right]$ succinylmonocholine. A similar hydrolysis procedure under mildly basic conditions was used to generate the breakdown products of atracurium and mivacurium, which were then preserved through acidification. The breakdown products of doxacurium were present as low-level contaminants in the doxacurium injectable liquid and were not deliberately generated.

\section{Sample Preparation}

Liquid specimens were aliquotted directly (typically 0.1 $\mathrm{ml}$ ) into $16 \times 125 \mathrm{~mm}$ glass tubes with Teflon-lined screw caps. Weighed tissue specimens were homogenized with aqueous $0.088 \%$ formic acid to yield homogenates of known dilution factor, typically $1 / 4$ or $1 / 10$, with 0.25 to $0.5 \mathrm{ml}$ aliquots taken. Paraoxon $(100 \mathrm{ng} / \mu \mathrm{l}$ in methanol, $1 \mu \mathrm{l}$ ) was added to each sample to inhibit esterase activity. Internal standard $\left(\left[{ }^{2} \mathrm{H}_{4}\right]\right.$ succinylmonocholine, $1 \mathrm{ng} / \mu \mathrm{l}, 25 \mu \mathrm{l}$ ) was added and, for spiked samples, a small-volume (typically $2-20 \mu \mathrm{l}$ ) of a spiking solution containing all the analytes (except succinylcholine) at known concentration $(1 \mathrm{ng} / \mu \mathrm{l}$ or $10 \mathrm{ng} / \mu \mathrm{l})$ was added. After the samples were vortexed, sufficient 
aqueous $0.044 \%$ formic acid was added to each specimen to bring its total volume to $1.0 \mathrm{ml}$, and the samples were vortexed again. Using repipettor bottles (Kendall, Mansfield, MA), $2.5 \mathrm{ml}$ of methanol and $1.25 \mathrm{ml}$ of chloroform were added to form the monophasic Bligh and Dyer mixture. The specimens were then capped and placed on an automatic rotator for $30 \mathrm{~min}$. Following the addition via repipettor of $1.5 \mathrm{ml}$ hexane and 0.75 $\mathrm{ml}$ chloroform to render the system biphasic, the capped samples were returned to the automatic rotator for $5 \mathrm{~min}$. The specimens were then centrifuged on a tabletop centrifuge at $3000 \mathrm{rpm}$ for $5 \mathrm{~min}$, following which the upper (aqueous) layer was transferred using plastic disposable pipettes to $10 \mathrm{ml}$ conical screwcapped glass tubes. The initial extracts were then evaporated to dryness under a stream of nitrogen at $55^{\circ} \mathrm{C}$ on a TurboVap (Zymark, Hopkinton, MA); this step typically required $90 \mathrm{~min}$ and, if necessary, samples were stored in this dry condition overnight at $4{ }^{\circ} \mathrm{C}$.

The samples were reconstituted with $2 \mathrm{ml}$ of aqueous $0.1 \%$ HFBA, sonicated for $5 \mathrm{~min}$, and vortexed. The following ion pairing solid-phase extraction procedure was performed either manually using a vacuum or positive pressure manifold set-up or robotically using RapidTrace devices (Zymark). The $\mathrm{C}_{18}$ extraction columns were conditioned twice with $2.5 \mathrm{ml}$ of $0.1 \%$ HFBA/methanol, then equilibrated twice with $2.5 \mathrm{ml}$ of aqueous $0.1 \%$ HFBA. The samples were then loaded and the columns were rinsed twice with $1 \mathrm{ml}$ of aqueous $0.1 \%$ HFBA, followed by a rinse with $0.75 \mathrm{ml}$ of $0.1 \% \mathrm{HFBA} / 15 \%$ methanol/water. The samples were eluted into $12 \times 75 \mathrm{~mm}$ glass tubes using two successive passes with $1 \mathrm{ml}$ of $0.1 \%$ HFBA/ $80 \%$ methanol/ water, followed by two successive passes with $1 \mathrm{ml}$ of $0.1 \%$ HFBA $/ 90 \%$ methanol/water. The combined eluates were then evaporated to dryness under a stream of nitrogen at $55^{\circ} \mathrm{C}$ on a TurboVap (30-45 min). The dry samples were reconstituted with brief sonication and vortexing in $0.2 \mathrm{ml}$ of aqueous $0.1 \% \mathrm{HFBA}$, and centrifuged for $5 \mathrm{~min}$ at $3000 \mathrm{rpm}$. The supernatants were transferred to plastic autosampler vials with conical interiors; the vials were capped with Teflon-lined caps, and $15 \mu \mathrm{l}$ aliquots were analyzed by LC-MS/MS.

\section{Liquid Chromatography-Tandem Mass Spectrometry}

The liquid chromatographic system consisted of two Shimadzu (Tokyo, Japan) LC-10ADVP pumps, a Shimadzu Sil-HTC autosampler, a Shimadzu FCV-10ALVP flow controller, two Shimadzu DGU-14A solvent degassers, and a Shimadzu CTO-10ASVP column oven. The column was a Thermo (Bellefonte, PA) Hypersil-

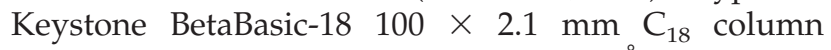
packed with $3 \mu \mathrm{m}$ particles with $150 \AA$ pores. The column temperature was maintained at $37^{\circ} \mathrm{C}$. The ion-pairing solvent system consisted of Solvent $\mathrm{A}$, which was aqueous $0.1 \%$ HFBA, and Solvent B, which was $0.1 \%$ HFBA/methanol. The initial mobile phase was $5 \%$ Solvent B at a flow rate of $0.1 \mathrm{ml} / \mathrm{min}$. After injection, the initial mobile phase conditions were maintained for $6 \mathrm{~min}$, at which time a linear gradient was initiated, achieving 95\% Solvent B at $20 \mathrm{~min}$. At $26 \mathrm{~min}$, the solvent composition was switched back to $5 \%$ Solvent B and the flow rate increased to $0.2 \mathrm{ml} / \mathrm{min}$ to re-equilibrate the column with the initial mobile phase. The flow rate was restored to $0.1 \mathrm{ml} / \mathrm{min}$ at $35.1 \mathrm{~min}$, with total run time of $35.2 \mathrm{~min}$.

The effluent from the LC system was directly introduced (with no flow splitting) into the electrospray ion source of a Q-TOF tandem mass spectrometer (Micromass, Manchester, UK). The Q-TOF was a Q-TOF I upgraded with a $4 \mathrm{GHz}$ time-to-digital converter. Nitrogen was used as the nebulizing and desolvation gas, with the source operated at $120^{\circ} \mathrm{C}$ and the desolvation gas at $425^{\circ} \mathrm{C}$. The capillary was operated at $3500 \mathrm{~V}$. Argon was used as the collision gas, with the collision gas pressure optimized to maximize the overall yield of product ions from the analytes of interest $(\sim 16 \mathrm{psi}$ indicated head pressure with the standard controlled leak into the collision cell). Cone voltages and laboratory frame-of-reference collision energies used for each of the analytes are delineated in Table 3. MS1 was operated at relatively low resolution (low mass and high mass settings of 5-10, representing an $\mathrm{m} / \mathrm{z}$ window of 3-5) to maximize the transmission of the precursors and thus enhance overall sensitivity. MS2 was operated at a resolution of 5000 to 7000 , representing a good overall balance between sensitivity and resolution with this instrument configuration.

\section{Organization of a Typical Analytical Run}

The analysis of biological specimens typically involved quadruplicate aliquots, two of which were treated as native specimens and two of which were spiked at two different levels with known amounts of a mixture of all of the analytes except succinylcholine, (which was excluded for initial analyses since it is seldom detected and since its breakdown to succinylmonocholine would distort the quantification of that analyte). As an alternative, one of the native aliquots often represented a standard dilution (by a factor of two) of the other native specimen, with the latter identical in volume and dilution factor to the spiked specimens. Control specimens included a reagent blank, blank human serum, blank human serum without internal standard, and several low-level standards prepared in blank serum. Analytical specimens involving positive findings were typically subjected to repeat analysis with the instrument monitoring only the analytes of interest, and with spiking levels and/or dilution factors adjusted as necessary to facilitate quantification. On the rare occasions when succinylcholine itself was detected during initial analysis, the specimens were re-analyzed using $\left[{ }^{2} \mathrm{H}_{8}\right]$ succinylcholine as the internal standard, with additional specimens and standards spiked with appro- 
Table 3. Analytical parameters and tandem mass spectrometric data for the various analytes included in these studies

\begin{tabular}{|c|c|c|c|c|c|}
\hline Analyte & Parent $m / z$ & $\begin{array}{l}\text { Retention } \\
\text { time (min) }\end{array}$ & $\begin{array}{c}\text { Cone } \\
\text { voltage (V) }\end{array}$ & $\begin{array}{l}\text { Collision } \\
\text { energy }(\mathrm{eV})\end{array}$ & $\begin{array}{l}\text { Significant product ions }[\mathrm{m} / \mathrm{z} \text { (relative } \\
\text { abundance)] }\end{array}$ \\
\hline Succinylmonocholine & 204 & 14.25 & 24 & 23 & $99(53 \%), 101(24 \%), 145(100 \%)$ \\
\hline$\left[{ }^{2} \mathrm{H}_{4}\right]$ Succinylmonocholine & 208 & 14.2 & 24 & 23 & $103(63 \%), 101(17 \%), 149(100 \%)$ \\
\hline Succinylcholine & $145\left(2^{+}\right)$ & 18.9 & 22 & 12 & $\begin{array}{l}79.5\left(2^{+}, 8 \%\right), 93.5\left(2^{+}, 33 \%\right), 115.6\left(2^{+}\right. \\
100 \%), 145,1\left(\mathrm{M}^{2+}, 25 \%\right), 171(6 \%), 230 \\
(3 \%)\end{array}$ \\
\hline Choline & 104 & 11.9 & 35 & 16 & $45(<1 \%), 60(2 \%), 104\left(\mathrm{M}^{+}, 100 \%\right)$ \\
\hline$\left[{ }^{2} \mathrm{H}_{9}\right]$ Choline & 113 & 11.72 & 35 & 16 & $45(<1 \%), 69(2 \%), 113\left(\mathrm{M}^{+}, 100 \%\right)$ \\
\hline Pancuronium & $286\left(2^{+}\right)$ & 21.2 & 25 & 16 & $\begin{array}{l}100(27 \%), 206.6\left(2^{+}, 75 \%\right), 236.6\left(2^{+}, 26 \%\right), \\
286\left(\mathrm{M}^{2+}, 23 \%\right), 332(13 \%), 430(100 \%), 472 \\
(34 \%)\end{array}$ \\
\hline Des-acetyl pancuronium & $265\left(2^{+}\right)$ & 20.9 & 25 & 16 & $\begin{array}{l}100(24 \%), 206.6\left(2^{+}, 5 \%\right), 265\left(\mathrm{M}^{2+}, 100 \%\right) \\
388(7 \%), 430(28 \%)\end{array}$ \\
\hline Des-diacetyl pancuronium & $244\left(2^{+}\right)$ & 20.9 & 25 & 16 & $\begin{array}{l}100(17 \%), 185.6\left(2^{+}, 5 \%\right), 244\left(\mathrm{M}^{2+}, 100 \%\right), \\
\quad 388(22 \%)\end{array}$ \\
\hline Vecuronium & 557 & 21.4 & 45 & 35 & $\begin{array}{c}100(66 \%), 338(53 \%), 356(68 \%), 398(32 \%), \\
416(16 \%), 497(14 \%), 557\left(\mathrm{M}^{+}, 100 \%\right)\end{array}$ \\
\hline Des-acetyl vecuronium & 515 & 21.2 & 45 & 35 & $\begin{array}{c}100(68 \%), 338(28 \%), 356(70 \%), 374(52 \%) \\
398(13 \%), 416(16 \%), 515\left(\mathrm{M}^{+}, 100 \%\right)\end{array}$ \\
\hline Des-diacetyl vecuronium & 473 & 21.25 & 45 & 35 & $\begin{array}{l}100(62 \%), 356(42 \%), 374(39 \%) 473\left(\mathrm{M}^{+},\right. \\
100 \%)\end{array}$ \\
\hline Tubocurarine & 609 & 20.4 & 50 & 38 & $\begin{array}{l}174(46 \%), 192(22 \%), 267(16 \%), 284(37 \%), \\
297(83 \%), 310(22 \%), 386(100 \%), 398 \\
(14 \%), 458(13 \%), 521(29 \%), 533(28 \%), 548 \\
(15 \%), 564(96 \%), 609\left(\mathrm{M}^{+}, 74 \%\right)\end{array}$ \\
\hline Rocuronium & 529 & 21.0 & 35 & 32 & $\begin{array}{c}112(29 \%), 340(13 \%), 358(21 \%), 376(13 \%), \\
413(17 \%), 487(100 \%), 529\left(\mathrm{M}^{+}, 84 \%\right)\end{array}$ \\
\hline Des-acetyl rocuronium & 487 & 21.05 & 35 & 32 & $\begin{array}{l}112(33 \%), 358(23 \%), 376(13 \%), 445(84 \%), \\
487\left(\mathrm{M}^{+}, 100 \%\right)\end{array}$ \\
\hline Atracurium & $464\left(2^{+}\right)$ & 21.7 & 35 & 21 & $\begin{array}{l}151(42 \%), 157(22 \%), 165(27 \%), 174(12 \%), \\
189(100 \%), 204(11 \%), 244(33 \%), 296 \\
(14 \%), 307(91 \%), 314(11 \%), 327(60 \%), 358 \\
(27 \%), 370(20 \%), 412(16 \%), 464\left(\mathrm{M}^{2+},\right. \\
58 \%), 516(13 \%), 601(43 \%), 763(5 \%)\end{array}$ \\
\hline Mivacurium & $514\left(2^{+}\right)$ & 21.9 & 32 & 24 & $\begin{array}{c}181(14 \%), 189(65 \%), 256(13 \%), 258(16 \%), \\
320(33 \%), 342(100 \%), 357(46 \%), 428 \\
(31 \%), 514\left(\mathrm{M}^{2+}, 57 \%\right), 600(25 \%), 626 \\
(8 \%), 669(12 \%), 671(43 \%), 833(3 \%)\end{array}$ \\
\hline Doxacurium & $517\left(2^{+}\right)$ & 22.6 & 35 & 25 & $\begin{array}{c}181(39 \%), 188(20 \%), 195(91 \%), 204(18 \%), \\
219(100 \%), 330(48 \%), 356(18 \%), 387 \\
(37 \%), 426(16 \%), 458(26 \%), 517\left(\mathrm{M}^{2+}\right. \\
44 \%), 576(21 \%), 647(51 \%), 839(8 \%)\end{array}$ \\
\hline Laudanosine & $358[\mathrm{M}+\mathrm{H}]^{+}$ & 20.6 & 35 & 23 & $\begin{array}{l}151(26 \%), 165(10 \%), 189(38 \%), 206(100 \%) \\
\quad 327(15 \%), 358\left([\mathrm{M}+\mathrm{H}]^{+}, 13 \%\right)\end{array}$ \\
\hline $\begin{array}{l}\text { Atracurium quaternary } \\
\text { acid }\end{array}$ & 430 & 20.1 & 35 & 23 & $\begin{array}{l}116(89 \%), 151(41 \%), 165(23 \%), 174(14 \%), \\
189(91 \%), 296(16 \%), 327(55 \%), 370(34 \%), \\
430\left(\mathrm{M}^{+}, 100 \%\right)\end{array}$ \\
\hline $\begin{array}{l}\text { Atracurium quaternary } \\
\text { alcohol }\end{array}$ & 516 & 20.7 & 35 & 25 & $\begin{array}{l}151(10 \%), 165(6 \%), 189(15 \%), 202(100 \%), \\
327(12 \%), 370(42 \%), 412(6 \%), 430(4 \%), \\
516\left(\mathrm{M}^{+}, 51 \%\right)\end{array}$ \\
\hline $\begin{array}{l}\text { Atracurium quaternary } \\
\text { monoacrylate }\end{array}$ & 570 & 22.0 & 35 & 30 & $\begin{array}{c}151(9 \%), 165(7 \%), 189(18 \%), 256(100 \%), \\
327(12 \%), 370(16 \%), 570\left(\mathrm{M}^{+}, 17 \%\right)\end{array}$ \\
\hline $\begin{array}{l}\text { Mivacurium quaternary } \\
\text { Acid }\end{array}$ & 600 & 21.2 & 35 & 28 & $\begin{array}{l}189(14 \%), 213(28 \%), 256(100 \%), 357(8 \%) \\
428(10 \%), 600\left(\mathrm{M}^{+}, 50 \%\right)\end{array}$ \\
\hline $\begin{array}{l}\text { Mivacurium Quaternary } \\
\text { alcohol }\end{array}$ & 446 & 20.2 & 35 & 25 & $\begin{array}{l}102(100 \%), 165(11 \%), 181(21 \%), 189(68 \%), \\
195(15 \%), 357(22 \%), 359(18 \%), 402(19 \%), \\
446\left(\mathrm{M}^{+}, 89 \%\right)\end{array}$ \\
\hline $\begin{array}{l}\text { Doxacurium quaternary } \\
\text { alcohol }\end{array}$ & 476 & 21.3 & 45 & 30 & $\begin{array}{l}102(52 \%), 181(97 \%), 188(63 \%), 195(67 \%), \\
204(33 \%), 219(100 \%), 235(16 \%), 250 \\
(25 \%), 266(17 \%), 281(17 \%), 294(17 \%), 341 \\
(14 \%), 356(33 \%), 389(14 \%), 401(11 \%), 432 \\
(14 \%), 476\left(\mathrm{M}^{+}, 25 \%\right)\end{array}$ \\
\hline $\begin{array}{l}\text { Doxacurium quaternary } \\
\text { acid }\end{array}$ & 576 & 21.2 & 45 & 32 & $\begin{array}{l}159(38 \%), 181(25 \%), 188(16 \%), 195(36 \%), \\
202(100 \%), 219(64 \%), 356(17 \%), 387 \\
(15 \%), 458(17 \%), 576\left(\mathrm{M}^{+}, 55 \%\right)\end{array}$ \\
\hline Bretylium & 242 & 20.0 & 32 & 34 & $90(15 \%), 169(100 \%)$ \\
\hline
\end{tabular}


priate amounts of succinylcholine. Similarly, occasional samples were re-analyzed for choline using $\left[{ }^{2} \mathrm{H}_{9}\right]$ choline as an internal standard. Quantitative estimation of positive findings was based upon a straightforward calculation using the method of standard additions, generally taking into account the response of the internal standard.

\section{Results and Discussion}

All of these compounds (except laudanosine) are precharged, with pancuronium, atracurium, mivacurium, and doxacurium doubly charged. The fixed positive charges on these compounds necessarily imparts hydrophilicity to that portion of the molecule, but most of these compounds also have substantial portions that are nonpolar in character. This nonpolar character probably explains observations during initial studies, which suggested substantial binding of drugs such as pancuronium to membranous constituents of tissues, to an extent that aqueous based and standard liquid-liquid extractions resulted in poor recoveries. The Bligh and Dyer mixture, which is a monophasic blend of water, methanol, and chloroform, was originally used to disrupt cellular membranes for the purpose of isolating membrane lipids. The modified variant of the Bligh and Dyer procedure described here uses hexane and chloroform instead of water and chloroform to render the system biphasic. The hexane was incorporated to reduce the polarity of the organic phase and drive the analytes into the aqueous phase.

The precharged character of these quaternary compounds (and the basic character of laudanosine) facilitates the formation of lipophilic ion pairs between these compounds and perfluorinated alkanoic acids such as trifluoroacetic acid and heptafluorobutyric acid. In general, the degree to which such ion pairs adhere to reverse phase materials such as $C_{18}$ increases as the length of the chain of the perfluorinated acid increases [4]. This is consistent with the observations during these studies. The use of heptafluorobutyric acid provided better overall performance, both for the solid-phase extraction and for the liquid chromatography, than did the use of trifluoroacetic acid. This was especially true of succinylmonocholine and choline, which are the least retained of all of these compounds on $\mathrm{C}_{18}$. The incorporation of heptafluorobutyric acid provided good recoveries of these compounds from the solid-phase extraction, and highly reproducible chromatographic retention times. This overall analytical strategy of using a modified Bligh and Dyer extraction in reverse compared with the original, followed by a reverse phase ion pairing extraction, provides excellent recoveries of these challenging compounds from most tissue specimens (based upon recoveries from spiked tissue homogenates).

Product ion spectra of succinylcholine, succinylmonocholine, and the internal standard $\left[{ }^{2} \mathrm{H}_{4}\right]$ succinylmonocholine are shown in Figure 1, with the fragmentation pattern of succinylmonocholine depicted in
Figure 2. The abundances of the $m / z 99$ and 101 ions relative to each other were quite reproducible, but the abundance of these two relative to the more intense $\mathrm{m} / \mathrm{z}$ 145 ion occasionally exhibited some variability, such that the abundance of the $\mathrm{m} / \mathrm{z} 99$ ion relative to the $\mathrm{m} / \mathrm{z}$ 145 ion could be as little as $10 \%$ or as high as $70 \%$ under nominally identical conditions. This probably reflects variations in the internal energy content due to minor fluctuations in ion source conditions or subtle matrix effects upon the desolvation process. With the low collision energy involved ( $23 \mathrm{eV}$ in the laboratory frame of reference), small changes in internal energy content can have a substantial effect on fragmentation pathways and, thus, product ion intensity ratios. Fortunately, on the occasions when this was observed, this posed no problem with identifying succinylmonocholine because alterations in internal energy content were similarly reflected in the averaged product ion spectrum of the $\left[{ }^{2} \mathrm{H}_{4}\right]$ succinylmonocholine obtained during the same analysis, as would be expected for isotopically labeled material. Variations in product ion intensity ratios were less of an issue with the larger compounds.

Product ion spectra of pancuronium, vecuronium, tubocurarine, and rocuronium are shown in Figure 3. These are some of the most commonly encountered of the larger (and longer acting) quaternary neuromuscular blocking drugs. Because of the large number of compounds involved in these studies, complete spectra are not shown for all of the compounds. Rather, the product ion spectral data are summarized in Table 3 along with other analytical parameters pertinent to each analyte.

Not all of these compounds are monitored during typical analyses of biological specimens in this laboratory. Several of these compounds elute at very similar retention times, and monitoring for all of them would compromise overall sensitivity due to the necessity of overlapping product ion scanning functions. Some of the parent compounds are seldom detected in intact form. Succinylcholine, atracurium, mivacurium, and doxacurium are all symmetric bis-esters, each containing two quaternary ammonium functions, one at either end of the molecule. Not only are these compounds potentially subject to the actions of endogenous esterase enzymes, but they are also inherently chemically unstable, readily undergoing hydrolysis (especially under basic conditions) to yield quaternary alcoholic and quaternary acidic breakdown products. Atracurium also undergoes chemical degradation to yield the alkaloid laudanosine and a quaternary monoacrylate as breakdown products $[15,16]$. The instability of these four drugs is such that the parent compounds often do not survive the analytical process, even with spiked specimens; this is especially true for atracurium and mivacurium. Based upon the experience of this laboratory, laudanosine and atracurium quaternary acid are the breakdown products most useful for initial testing to indicate atracurium exposure. Similarly, mivacurium quaternary alcohol and doxacurium quaternary alcohol 
(a)
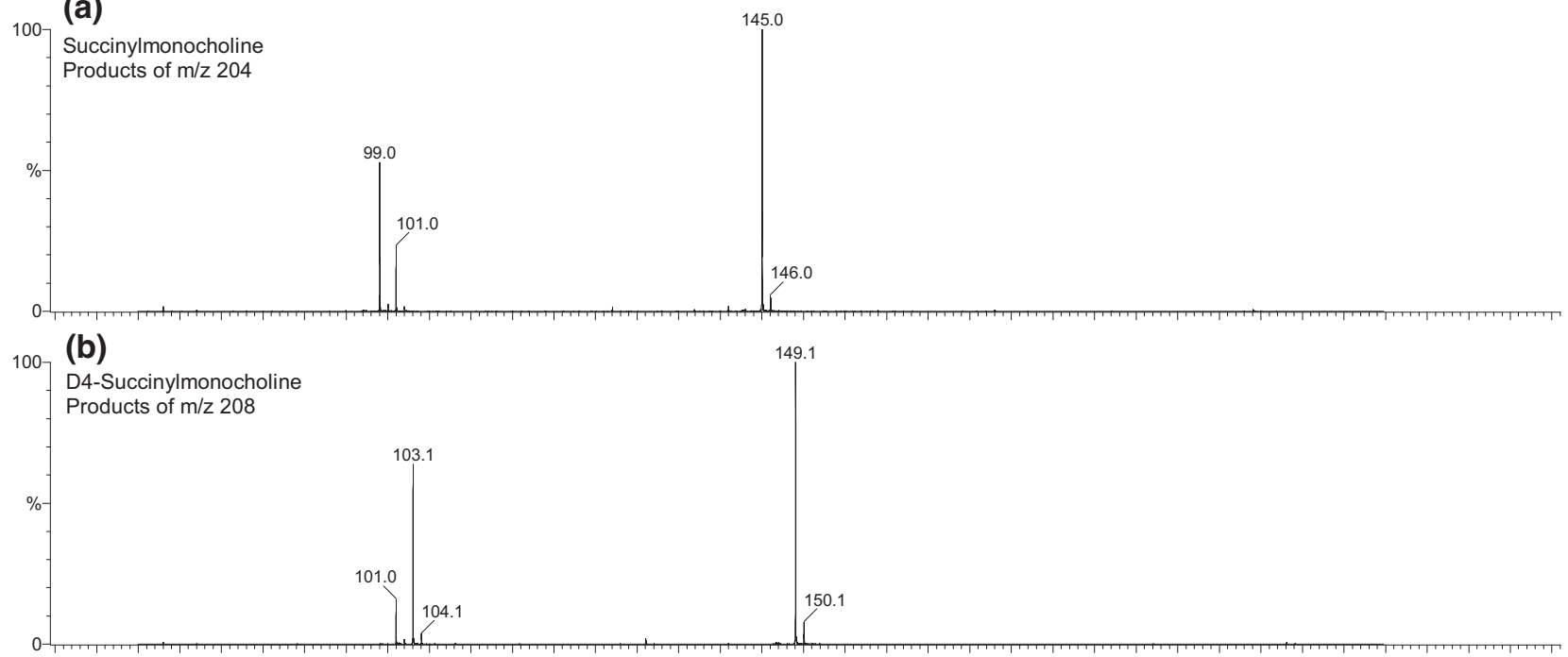

(c)

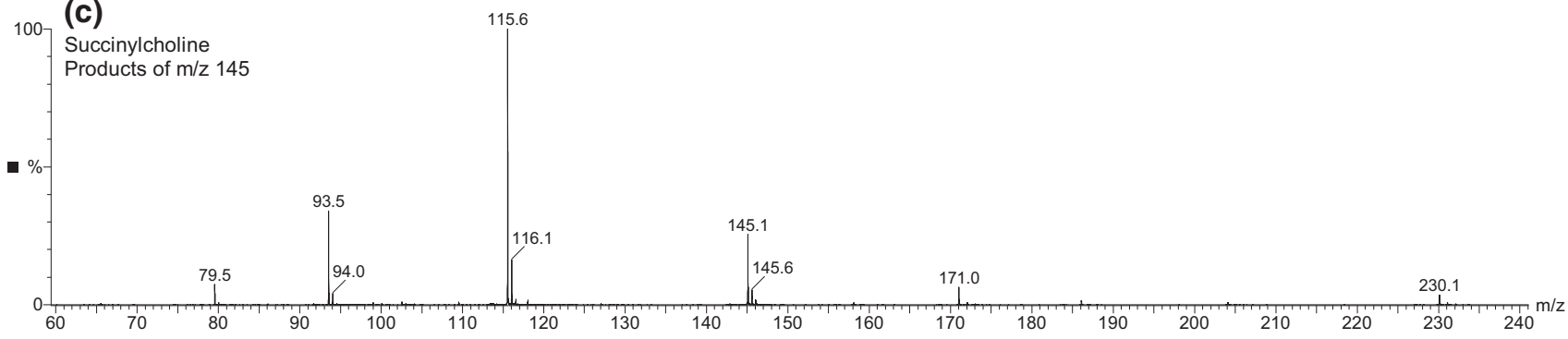

Figure 1. Product ion spectra of succinylcholine, succinylmonocholine, and the internal standard $\left[{ }^{2} \mathrm{H}_{4}\right]$ succinylmonocholine.

are the most useful for initially indicating mivacurium and doxacurium, respectively, (see Table 2). Since succinylcholine and doxacurium elute in completely separate retention windows, they are routinely monitored despite the fact that they are seldom detected intact in biological specimens. Figure 4 depicts high-resolution mass chromatograms (one ion per analyte) from a spiked brain specimen (spiked at $80 \mathrm{ng} / \mathrm{g}$ ) showing the 13 analytes (representing nine drugs plus the internal standard) routinely monitored in this laboratory during initial tests of biological specimens. If one or more of

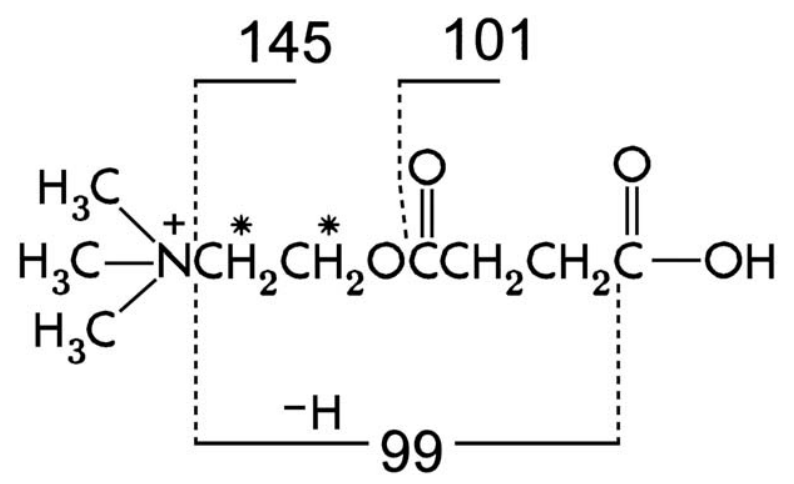

Figure 2. The fragmentation pattern of succinylmonocholine under low-energy CAD conditions. The asterisks indicate the positions of the labels in the deuterated material. these breakdown products of an unstable drug is detected, the specimens can be reinjected with appropriate scanning functions added (and extraneous functions removed) to monitor for other drug breakdown products and for the parent drug itself. (It should be noted that the weak signal corresponding to succinylcholine in Figure 4 is due to the trace amount of residual succinylcholine in the succinylmonocholine preparation. Succinylcholine itself is not routinely included in the spiked samples for reasons cited above.)

The brain specimen involved in Figure 4 was positive for vecuronium and succinylmonocholine. The samples from that analysis were reinjected with most of the extraneous scanning functions removed to permit focusing the analysis upon vecuronium (and succinylmonocholine, data not shown). High-resolution mass chromatograms representing significant ions for vecuronium from the native (unspiked) specimen are shown in Figure 5a, with corresponding traces for the specimen spiked at the 80 $\mathrm{ng} / \mathrm{g}$ level shown in Figure 5b. For the native specimen, each trace exhibits a single chromatographic peak at the same retention time, with intensity ratios and retention time appropriate for vecuronium (the upper right hand corner of each trace shows the $\mathrm{m} / \mathrm{z}$ range for that trace and, immediately below, the peak intensity for that trace). The spiked specimen shows a single chromatographic peak for each trace with no evidence of chromatographic inhomo- 


\section{(a)}
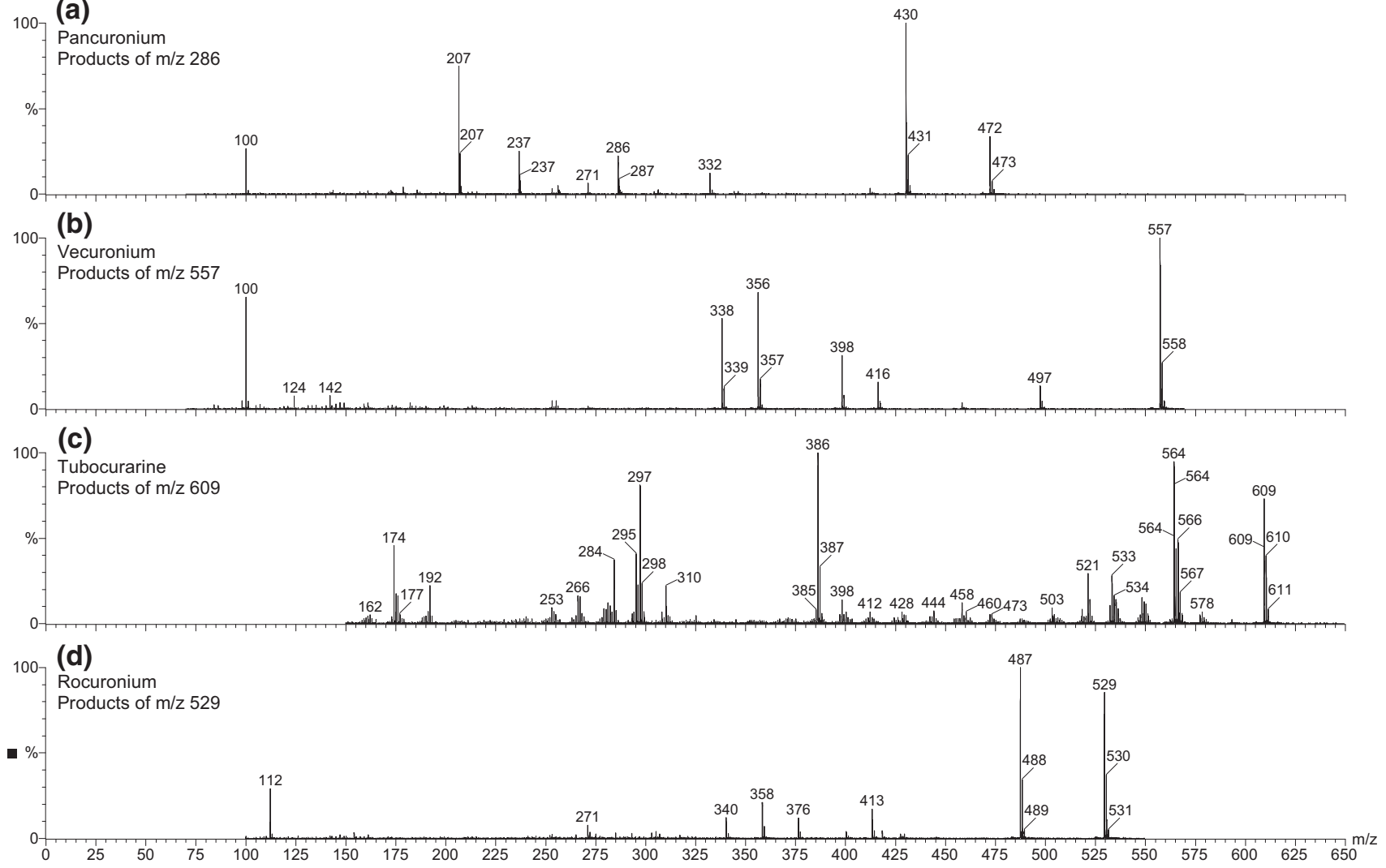

Figure 3. Product ion spectra of pancuronium, vecuronium, tubocurarine, and rocuronium.

geneity, and the peak intensity of each trace is increased by a factor of $\sim 4.5$ compared to the native specimen (in terms of absolute signal intensity). Product ion spectra, combined across the chromatographic peak of interest, for the native and spiked specimens are shown in Figure 6a. The spectra have an obvious similarity, with all of the ions characteristic of vecuronium (see Figure $3 b$ ) present and in the appropriate ratios, with the absolute signal intensity suitably increased with the spiked specimen as compared to the native specimen. Figure $6 \mathrm{~b}$ shows expanded portions of these spectra with the vertical axes linked, demonstrating the isobaric nature of the signal increase with the spiked specimen for the $\mathrm{m} / \mathrm{z} 356$ ion. This isobaric signal increase occurred with all of the ions characteristic of vecuronium. Additional and apparently spurious ions in the spectra, such as the $\mathrm{m} / \mathrm{z} 129$ ion, were demonstrably chromatographically distinct from the vecuronium ions, i.e., were due to a neighboring and overlapping chromatographic peak. Based on this analysis, using the method of standard additions for chromatographic peak areas and taking into account the response of the internal standard, this specimen, as it was received, contained vecuronium at a level of $\sim 28 \mathrm{ng} / \mathrm{g}$ of brain (without the internal standard taken into account, the calculated result was 25 $\mathrm{ng} / \mathrm{g}$ ).

The foregoing typical example demonstrates that the criteria for defining a positive finding are based upon comparing the analyses of native (unspiked) and spiked samples. The spiked specimens, as matrix-matched positive controls, serve very important functions for both quantitative and especially qualitative purposes. Some of the criteria are applicable to the comparative product ion spectra, combined across the region of elution of a given analyte. Since these are full-scan data, all of the significant ions characteristic of the analyte must be observed with the native specimen. In comparing the combined spectra from the native and spiked samples, the absolute intensities of each of the characteristic product ions must increase with the spiked sample, and this increase must be isobaric at high resolution, with no mass spectrometric peak splitting, or the appearance of new ions in the high-resolution spectrum from the spiked specimen. The relative abundances of the observed product ions must be comparable between the two analyses. Correspondingly, high-resolution mass chromatograms of the various product ions must exhibit appropriate characteristics. Native specimens must exhibit chromatographically homogeneous comaximization of all significant ions at high resolution, at the appropriate ratios, with spiked specimens showing the same chromatographic homogeneity at appropriately increased intensity. All of these criteria must be met in order for a specimen to be considered positive for a given analyte. In the case of succinylmonocholine, it must also be observed that the analyte elutes from the chromatographic system just slightly later than the $\left[{ }^{2} \mathrm{H}_{4}\right]$ succinylmonocholine internal standard (typically 

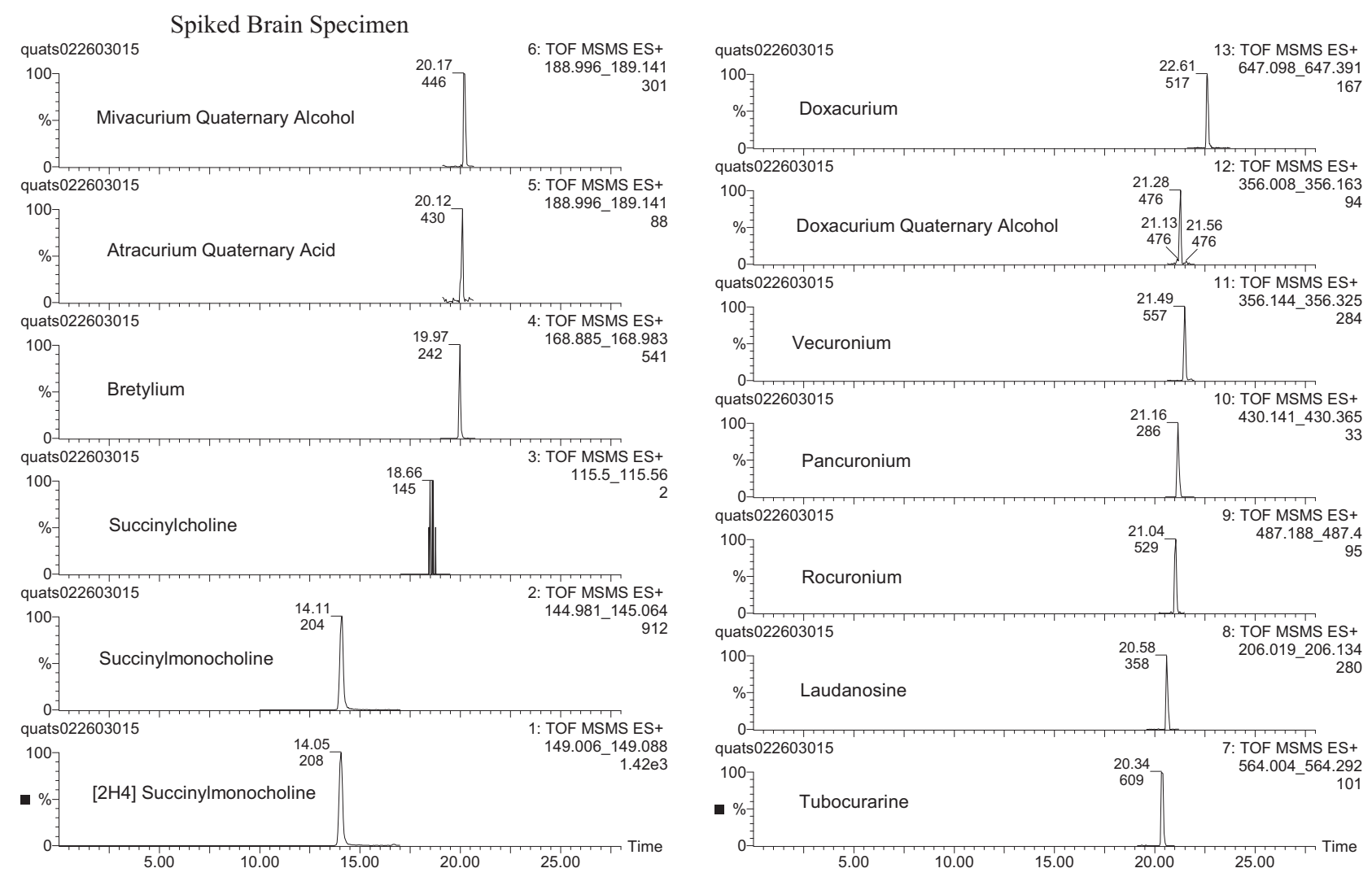

Figure 4. High-resolution mass chromatograms from a spiked brain specimen (spiked at $80 \mathrm{ng} / \mathrm{g}$ ) showing the 13 analytes (representing nine drugs plus the internal standard) routinely monitored during initial tests of biological specimens.

about three seconds later under the conditions described above).

Several of these compounds are potentially susceptible to esterase activity. The inclusion of paraoxon in all samples as an esterase inhibitor improved recoveries of the intact drugs, particularly with blood and plasma specimens, but also for the tissue specimens, most notably liver, that also exhibit esterase activity.

Table 4 presents a comparison of the quantitative results for succinylmonocholine in four forensic specimens using the method of standard additions versus a serum standard curve incorporating the deuterated internal standard. (These standard addition data were calculated using a straightforward standard addition calculation based upon peak areas without taking into account the response of the internal standard.) The decedent in Case 1 had been embalmed, then autopsied before burial, with the specimens stored frozen for several years. The decedent in Case 2 had been embalmed, buried several years, then exhumed and autopsied, with the specimens frozen for years. Of all the analytes in these studies, the only ones for which an isotopically labeled internal standard is available are succinylcholine, succinylmonocholine, and choline. Obviously, the best quantitative data are obtained when an isotopically labeled internal standard is used. For the other analytes, the method of standard additions is the most appropriate means of quantitative estimation because the quantitative data are necessarily matrix matched, and each specimen serves as its own control. The data in Table 4 demonstrate the validity of this approach because the numbers are essentially the same using the two approaches with an analyte for which a deuterated internal standard is available. The spiked specimens also serve additional quality control functions. They permit estimating recovery efficiency and detection limits for each specimen, and can identify an analytical failure. A few specimens have been identified over the years from which the quaternary ammonium analytes could not be recovered at any meaningful detection limit, and these specimens were identified by the fact that there was no recovery even with high spiking levels, and despite the fact that the rest of the run (serum standards, other spiked specimens, etc.) exhibited good recoveries. All analytes exhibited good stability under frozen conditions, but some analytes deteriorated with time under refrigerated or roomtemperature storage conditions.

During the course of these studies, it was discovered that succinylmonocholine is present at relatively low levels in normal fresh posthumous liver and kidney, typically at a level of less than $50 \mathrm{ng} / \mathrm{g}$ for each of these tissues, from human and nonhuman sources. This has not yet been thoroughly investigated. Succinylmono- 
(a)

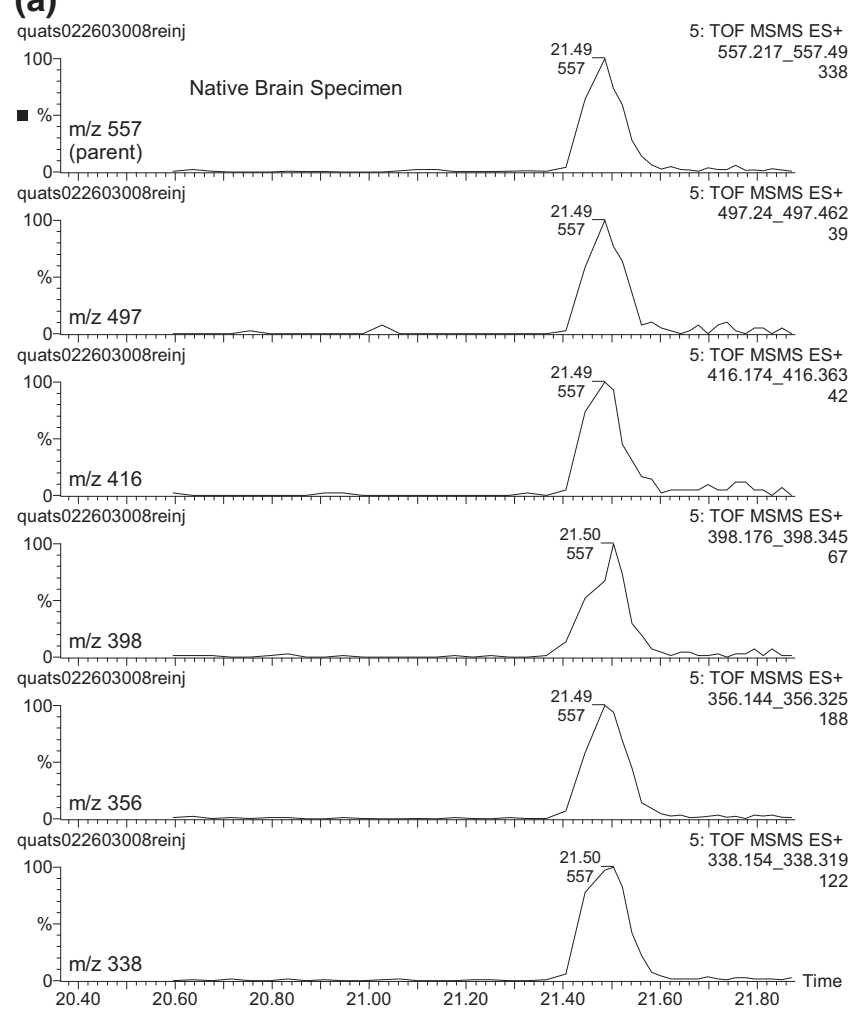

(b)

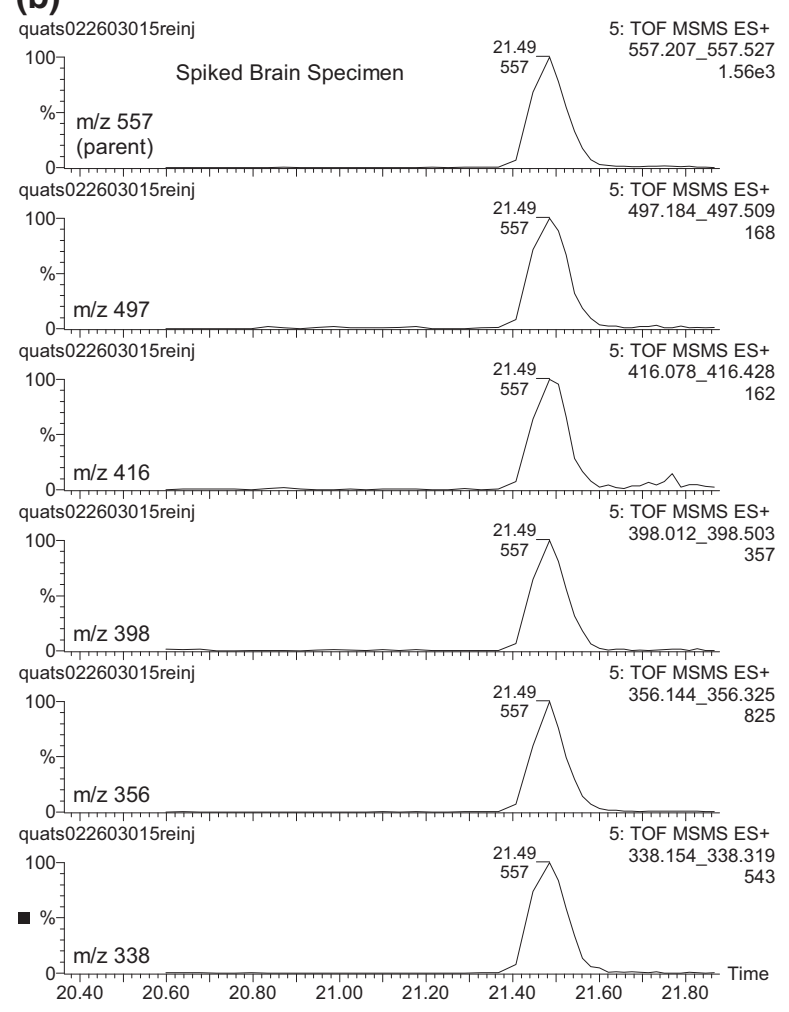

Figure 5. (a) High-resolution mass chromatograms representing significant ions for vecuronium from the native (unspiked) brain specimen from Figure 4. (b) Corresponding traces for the specimen spiked at the $80 \mathrm{ng} / \mathrm{g}$ level.

choline has not been observed in normal human blood, and thus far it has not been observed in normal brain. It is not known now whether succinylmonocholine is present in living tissue, or whether this represents a postmortem phenomenon (both succinic acid and choline are present at $\mu \mathrm{g} / \mathrm{ml}$ levels in human blood [30], and their concentrations may be high in the tissues as well). If succinylmonocholine is present in living tissues, the obvious pharmacologic implication is that succinylcholine and/or succinylmonocholine may be involved in cholinergic neurotransmission.

Another interesting observation from these studies is that several cases have been encountered involving both high concentrations of pancuronium and low concentrations of vecuronium. Some such cases involved documented exposure to pancuronium but no documented exposure to vecuronium. Structurally, vecuronium is N-demethylated pancuronium (see Table 1). It seems likely that the low levels of vecuronium observed in these cases were actually derived from the pancuronium, through either chemical or metabolic processes. The incorporation of analyzing for the desacetylated metabolites of pancuronium, vecuronium, and rocuronium into this analytical panel is a relatively recent development. One recent blood specimen involving high pancuronium levels also exhibited des-acetyl pancuronium, des-diacetyl pancuronium, vecuronium, and des-acetyl vecuronium.
Although the primary focus of the present paper is the analytical strategy itself, a brief description of its applicability is warranted. This overall analytical strategy is highly efficient, with recoveries of these analytes generally in the 80 to $95 \%$ range from human serum. The overall method was applicable to a broad range of sample types, exhibiting good recoveries and low detection limits (typically 2-10 $\mathrm{ng} / \mathrm{g}$ ) for most samples analyzed. These samples included biological fluids such as blood, serum, plasma, urine, vitreous fluid, and bile. The great majority of samples, however, were various types of tissues in various states of preservation as described above. As a general rule, good results were obtained with kidney, brain, diaphragm, spleen, lung, blood, serum, plasma, and urine. Poorer recoveries were generally observed with skeletal and heart muscle. Liver and bile generally gave good results, but occasional specimens gave poor recoveries. As a general rule, the best specimens for initial analysis for the neuromuscular blocking agents are kidney, brain, liver, and diaphragm. On the rare occasions when intact succinylcholine was identified, it was generally in urine or kidney. The question is occasionally asked as to why brain is a good specimen for these analyses, since quaternary compounds would not be expected to cross the blood-brain barrier. The most likely answer is because of the brain's tremendous blood supply; the brain is full of blood. At the microscopic level, at the 
(a)

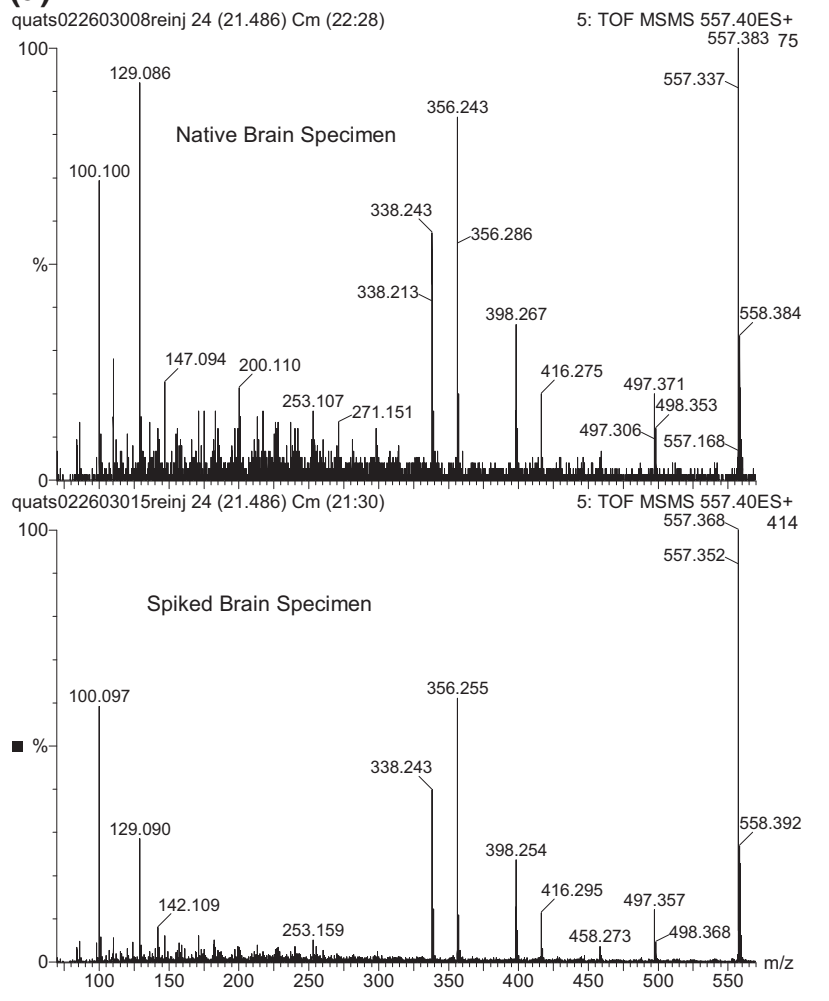

(b)

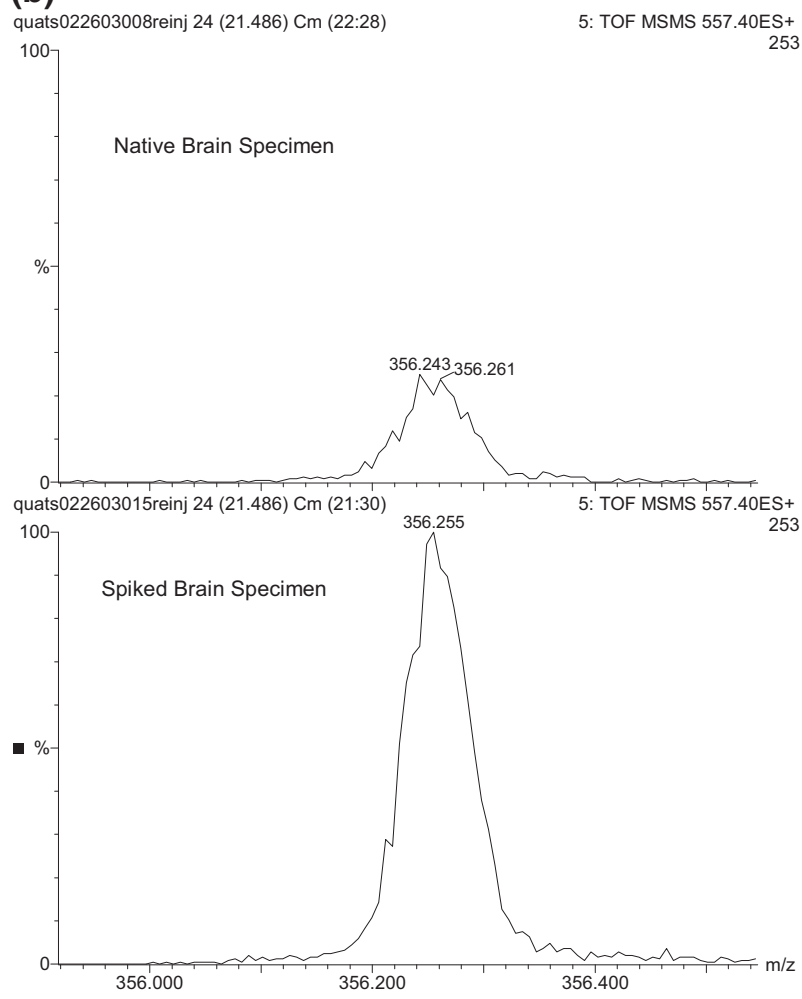

Figure 6. (a) Product ion spectra, combined across the chromatographic peak of interest, for the native and spiked brain specimens from Figure 5. (b) Expanded portions of the spectra from Figure 6 a with the vertical axes linked to the same absolute scale, demonstrating the isobaric nature of the signal increase with the spiked specimen for the $m / z 356$ ion. Similar isobaric increases were observed with all of the ions relevant to vecuronium for this specimen.

time of death, the quaternary compounds are located in the blood within the arteries, veins, and capillaries within the brain matrix, but at the macroscopic level after autopsy, the brain is a good specimen for these analyses. Since most of these analytes are more stable under mildly acidic conditions than under neutral or basic conditions, possibly the embalming process, which typically involves mildly acidic solutions, actually helps preserve these compounds in tissues.

Table 4. Comparison of the results of quantitative estimation using a standard curve based upon the

$\left[{ }^{2} \mathrm{H}_{4}\right]$ succinylmonocholine internal standard versus the method of standard additions (without taking into account the internal standard $)^{*}$

\begin{tabular}{|c|c|c|}
\hline Sample & $\begin{array}{l}\text { Succinylmonocholine } \\
\text { quantification with } \\
\text { internal } \\
\text { standardization } \\
\text { (ave. of } 4-8 \text { ), } \\
\text { ng/g of tissue }\end{array}$ & $\begin{array}{c}\text { Succinylmonocholine } \\
\text { Quantification } \\
\text { by Standard } \\
\text { Additions } \\
\text { (ave. of } 2-4 \text { ), } \\
\text { ng/g of tissue }\end{array}$ \\
\hline Case 1 kidney & 227 & 214 \\
\hline Case 1 spleen & 21 & 20 \\
\hline Case 1 brain & 42.5 & 52.6 \\
\hline Case 2 kidney & 50.3 & 48.8 \\
\hline
\end{tabular}

* Data for the two approaches were acquired on the same specimens within the same run. The two approaches give similar values.
The analytes most commonly encountered in submitted specimens have been pancuronium, vecuronium, and rocuronium. More seldom, atracurium and mivacurium have been encountered. With the latter two, the breakdown products of these drugs (vide supra) have been especially important. For atracurium, in most instances all four of its breakdown products were found, but little or no intact parent drug. In a few atracurium cases, the only breakdown products observed were the two smallest ones, atracurium quaternary acid and the alkaloid laudanosine. Similarly, for mivacurium, both of its breakdown products were generally observed, with little or no intact mivacurium found. An occasional specimen has been positive for tubocurarine.

Quite a number of interesting cases have been encountered during the course of these studies. There are at least two ongoing serial homicide investigations involving medical professionals as suspects, where succinylcholine may have been used as a murder weapon. In two separate cases involving anesthesiologists committing suicide, both cases involved high blood levels of pancuronium, in addition to high levels of sedativehypnotic drugs and opioids. Another interesting case involved what was ostensibly a death due to a fire. The pathologist in the case noted that the victim's blood 

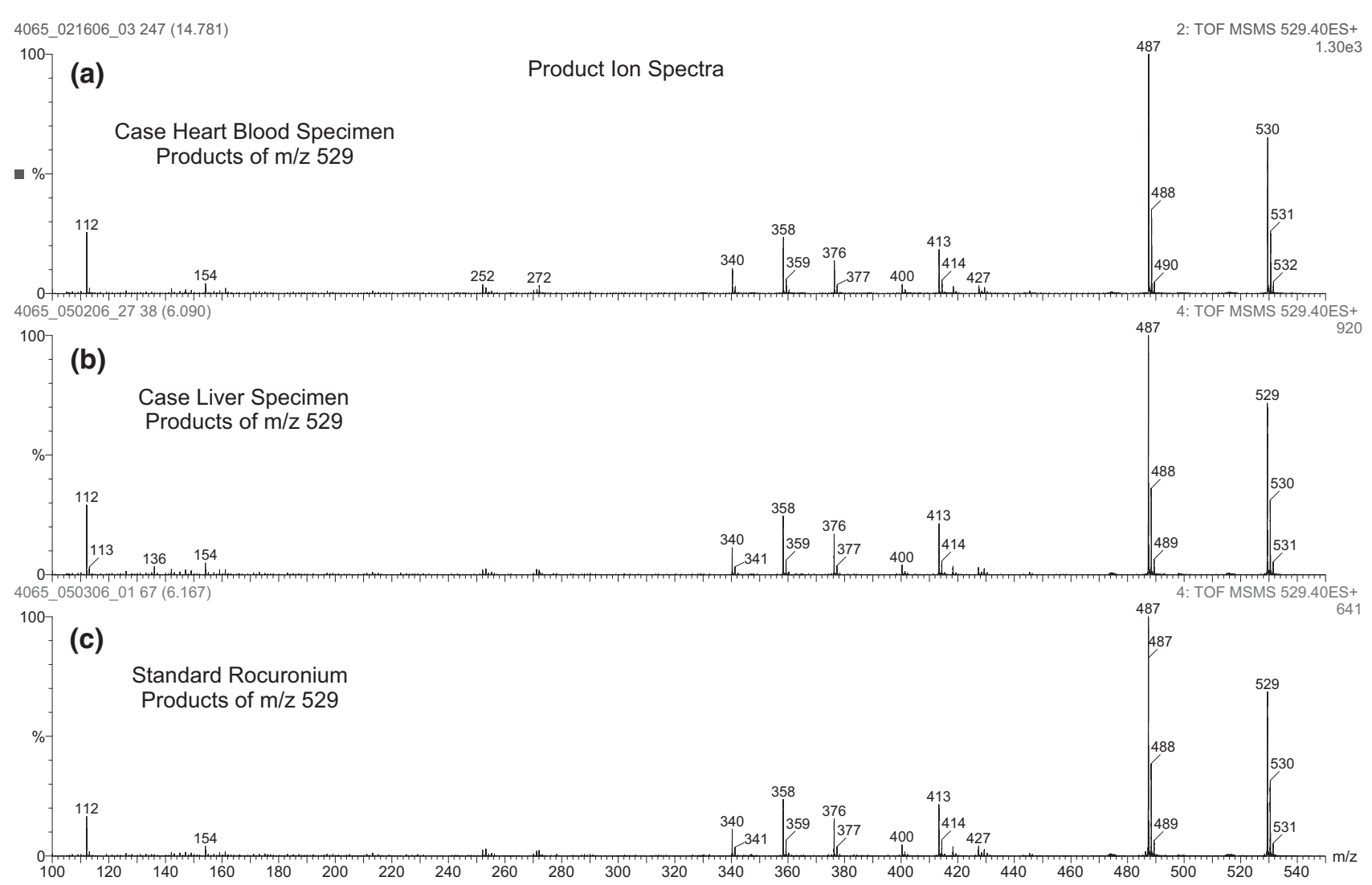

Figure 7. Product ion spectra, combined across the chromatographic peak of interest, for (a) heart blood from a suspected murder victim, (b) liver from that suspected victim, and (c) standard rocuronium extracted from spiked human serum.

carbon monoxide level was not elevated, which indicated that the victim was already dead when the fire occurred. The victim's spouse was a medical professional. Specimens of heart blood and liver tissue from the decedent were submitted to this laboratory for analysis for a wide variety of drugs, including the neuromuscular blocking agents. Significant findings from these specimens are depicted in Figure 7, which shows product ion spectra obtained from standard rocuronium and from the two case specimens. All of the chromatographic and mass spectrometric criteria described above were met, and rocuronium was unequivocally identified in both specimens from the decedent. The rocuronium concentration in the blood was 4.9 $\mu \mathrm{g} / \mathrm{mL}$, and the liver rocuronium concentration was $14.4 \mu \mathrm{g} / \mathrm{g}$. In another case involving a suspected homicide or suicide, the pathologist wondered whether a poisoning agent had been injected at the injection site where an insulin pump had been in place on the decedent (as was normal for this decedent), in an attempt to cover up the homicide or suicide. The excised injection site was divided into three layers, namely skin, fat, and underlying muscle. All three layers were positive for all four atracurium breakdown products.

This overall approach has also been useful for clinical work. Two recent clinical cases from separate parts of the country involved prolonged paralysis in pediatric patients following routine administration of vecuronium during surgical procedures. In both cases, the patients were paralyzed for more than three weeks after the last administration of the paralytic drug, and both patients had to be maintained on a respirator for that extended period of time. In both instances, the prolonged paralysis was explained by the persistence in the patients' bodies of both the parent drug and its active metabolite, des-acetyl vecuronium, which has about 50 to $70 \%$ of the parent drug's activity [31]. It is unknown why these two patients were unable to eliminate the drug and metabolite in a normal efficient fashion.

\section{Conclusions}

The overall analytical strategy described here reliably extracts quaternary ammonium neuromuscular blocking agents and their breakdown products from a wide variety of forensic sample matrices. Likely, this strategy will be applicable to other types of analytes with similar problematic characteristics, and to other types of samples, such as plant materials. With most specimens, detection limits were generally in the 2 to $10 \mathrm{ng} / \mathrm{g}$ range. While it might be possible to push the detection limits even lower, it is doubtful that findings below this level would be meaningful, particularly in court. The 
use of matrix matched spiked samples for both qualitative and quantitative control purposes is essential with the unique specimens encountered in a forensic setting.

The Q-TOF is an excellent platform for forensic analytical investigations, and is clearly superior to a tandem quadrupole for forensic LC-MS/MS. By providing full scan product ion spectra at high resolution and at high sensitivity, the Q-TOF provides a tremendous amount of analytical confidence for forensic work, where the qualitative findings are often the most important.

\section{Acknowledgments}

The authors are grateful for the participation and contributions of Special Agents Charles Quinzer and Marc LeBeau of the Federal Bureau of Investigation during the studies concerning the presence of succinylmonocholine in normal tissues (the discovery of which is largely attributable to the persistent efforts of Special Agent Quinzer). The authors are also grateful to Rosemarie D. Citrino of National Medical Services for her assistance during the comparison of quantitative determinations obtained using the method of standard additions versus those obtained via standard curves incorporating deuterated internal standardization, and to Meredith L. Atkins for her contributions in performing many of the extractions. This manuscript is dedicated to the memory of Dr. Fredric Rieders, whose long interest in this project inspired the rest of us in its pursuit.

\section{References}

1. Krull, I.; Swartz, M. Quantitation in method validation. LC-GC 1998, 16, 1084-1090.

2. Robinson, J. W. Undergraduate instrumental analysis revised and expanded, 5th ed.; Marcel Dekker: New York, 1995; pp 64, 65, 425-428.

3. Bligh, E. G.; Dyer, W. J. A rapid method of total lipid extraction and purification. Can. J. Biochem. Physiol. 1959, 37, 911-917.

4. Schaaper, W. M. M.; Voskamp, D.; Olieman, C. Perfluoroalkanoic acids as lipophilic ion-pairing reagents in reversed-phase liquid chromatography of peptides including secretin. J. Chromatogr. 1980, 195, 181-186.

5. Cirimele, V.; Villain, M.; Pepin, G.; Ludes, B.; Kintz, P. Screening procedure for eight quaternary nitrogen muscle relaxants in blood by high-performance liquid chromatography electrospray ionization mass spectrometry. J. Chromatogr. B Analyt. Technol. Biomed. Life Sci. 2003, 789, 107-113.

6. Epemolu, O.; Mayer, I.; Hope, F.; Scullion, P.; Desmond, P. Liquid chromatography/mass spectrometric bioanalysis of a modified $\gamma$ cyclodextrin (Org 25969) and rocuronium bromide (Org 9426) in guinea pig plasma and urine: Its application to determine the plasma pharmacokinetics of Org 25969. Rapid Commun. Mass Spectrom. 2002, 16, 1946-1952.

7. Kerskes, C. H.; Lusthof, K. J.; Zweipfenning, P. G.; Franke, J. P. The detection and identification of quaternary nitrogen muscle relaxants in biological fluids and tissues by ion-trap LC-ESI-MS. J. Anal. Toxicol. 2002, 26, 29-34.

8. Roy, J. J.; Boismenu, D.; Gao, H.; Mamer, O. A.; Varin, F. Measurement of succinylcholine concentration in human plasma by electrospray tandem mass spectrometry. Anal. Biochem. 2001, 290, 238-244.

9. Gao, L.; Ramzan, I.; Baker, B. Gas chromatographic-mass spectrometric assay for rocuronium with potential for quantifying its metabolite, 17-desacetylrocuronium, in human plasma. J. Chromatogr. B Biomed. Sci. Appl. 2001, 757, 207-214.

10. Farenc, C.; Enjalbal, C.; Sanchez, P.; Bressolle, F.; Audran, M.; Martinez, J.; Aubagnac, J. L. Quantitative determination of rocuronium in human plasma by liquid chromatography-electrospray ionization mass spectrometry. J. Chromatogr. A 2001, 910, 61-67.

11. Tang, F. P.; Leung, G. N.; Wan, T. S. Analyses of quaternary ammonium drugs in horse urine by capillary electrophoresis-mass spectrometry. Electrophoresis 2001, 22, 2201-2209.

12. Gutteck-Amsler, U.; Rentsch, K. M. Quantification of the aminosteroidal nondepolarizing neuromuscular blocking agents rocuronium and vecuronium in plasma with liquid chromatography-tandem mass spectrometry. Clin. Chem. 2000, 46, 1413-1414.

13. Klys, M.; Bialka, J.; Bujak-Gizycka, B. A case of suicide by intravenous injection of pancuronium. Leg. Med. (Tokyo) 2000, 2, 93-100.

14. Zhu, Y.; Wong, P. S.; Cregor, M.; Gitzen, J. F.; Coury, L. A.; Kissinger, P. T. In vivo microdialysis and reverse phase ion pair liquid chromatography/tandem mass spectrometry for the determination and identification of acetylcholine and related compounds in rat brain. Rapid Commun. Mass Spectrom. 2000, 14, 1695-1700.

15. Wang, P.; Zhang, H.; Stewart, J. T.; Bartlett, M. G. Simultaneous detection of cisatracurium, its degradation products, and propofol using positive ion detection followed by negative ion detection in a single LC/MS run. J. Pharm. Biomed. Anal. 1998, 17, 547-553.

16. Dear, G. J.; Harrelson, J. C.; Jones, A. E.; Johnson, T. E.; Pleasance, S. Identification of urinary and biliary conjugated metabolites of the neuromuscular blocker 51W89 by liquid chromatography/mass spectrometry. Rapid Commun. Mass Spectrom. 1995, 9, 1457-1464

17. Nisikawa, M.; Tatsuno, M.; Suzuki, S.; Tsuchihashi, H. The analysis of quaternary ammonium compounds in human urine by direct inlet electron impact ionization mass spectrometry. Forensic Sci. Int. 1991, 51, 131-138.

18. Briglia, E. J.; Davis, P. L.; Katz, M.; Dal Cortivo, L. A. Attempted murder with pancuronium. J. Forensic Sci. 1990, 35, 1468-1476.

19. Baker, T. R.; Vouros, P.; Rindgen, D.; Martyn, J. A. Mass spectrometric assay for determination of pancuronium and vecuronium in biological fluids utilizing the moving belt introduction system. Biomed. Environ. Mass Spectrom. 1990, 19, 69-74.

20. Somogyi, G.; Varga, M.; Prokai, L.; Dinya, Z.; Buris, L. Drug Identification problems in two suicides with neuromuscular blocking agents. Forensic Sci. Int. 1989, 43, 257-266.

21. Castagnoli, K. P.; Shinohara, Y.; Furuta, T.; Nguyen, T. L.; Gruenke, L. D.; Miller, R. D.; Castagnoli, N., Jr. Quantitative estimation of quaternary ammonium neuromuscular blocking agents in serum by direct insertion probe chemical ionization mass spectrometry. Biomed. Environ. Mass Spectrom. 1986, 13, 327-332.

22. Malthe-Sorenssen, D.; Odden, E.; Blanch, J.; Bugge, A.; Morland, J. Determination of succinyldicholine in different tissue sample from guinea pigs after injection of a single intravenous dose. Forensic Sci. Int. 1986, 32, 171-178.

23. Lukaszewski, T. The extraction and analysis of quaternary ammonium compounds in biological material by GC and GC/MS. J. Anal. Toxicol. $1985,9,101-108$.

24. Balkon, J.; Donnelly, B.; Rejent, T. A. Determination of succinylcholine in tissues by TLC, GC/NPD, and GC/MS. J. Anal. Toxicol. 1983, 7, 237-240.

25. Nordgren, I. K.; Forney, R. B.; Carroll, F. T.; Holmstedt, B. R.; Jaderholm-Ek, I.; Pettersson, B. M. Analysis of succinylcholine in tissues and body fluids by ion-pair extraction and gas chromatography-mass spectrometry. Arch. Toxicol. Suppl. 1983, 6, S339-S350.

26. Forney, R. B.; Carroll, F. T.; Nordgren, I. K.; Pettersson, B. M.; Holmstedt, B. Extraction, identification, and quantitation of succinylcholine in embalmed tissue. J. Anal. Toxicol. 1982, 6, 115-119.

27. Diamond, F. X.; Ballard, K. D.; Vickery, W. E.; Rieders, F.; Lund, A. Analysis of quaternary ammonium neuromuscular blocking agents in forensic tissue and fluid specimens by LC-MS/MS. Proceedings of the 48th ASMS Conference on Mass Spectrometry and Allied Topics; Long Beach, CA, June, 2000.

28. Ballard, K. D.; Vickery, W. E.; Citrino, R. D.; Diamond, F. X.; Rieders, F. Analysis of quaternary ammonium neuromuscular blocking agents in a forensic setting using LC-MS/MS with internal standardization on a Q-TOF. Proceedings of the 49th ASMS Conference on Mass Spectrometry and Allied Topics; Chicago, IL, May, 2001.

29. Ballard, K. D.; Vickery, W. E.; Nguyen, L. T.; Diamond, F. X.; Rieders, F. Quaternary ammonium neuromuscular blocking agents in forensics using a Q-TOF; the importance of degradation products and metabolites. Proceedings of the 51st ASMS Conference on Mass Spectrometry and Allied Topics; Montreal, Canada, June, 2003.

30. Lentner, C., Ed. GEIGY Scientific Tables, Vol. III: Physical chemistry, composition of blood, hematology, somatometric data; 8th ed. CIBA-GEIGY: West Caldwell, 1984; pp 96, -97, 108.

31. Baselt, R. C. Disposition of toxic drugs and chemicals in man, 7th ed; Biomedical Publications: Foster City, CA, 2004, pp 366-368 